\title{
DESEMPENHO INICIAL EM CAMPO DE LOTES DE SEMENTES DE MILHO TRATADAS COM PRODUTOS A BASE DE AMINOÁCIDOS
}

\author{
VANZOLINI, Silvelena ${ }^{1}$ \\ SILVEIRA, Tassio Garcia da ${ }^{2}$
}

Enviado em: 2009-06-23

Aprovado em: 2009-08-03

ISSUE DOI: $10.3738 / 1982.2278 .172$

\begin{abstract}
RESUMO: Com o objetivo de avaliar o desempenho inicial em campo de lotes de sementes de milho tratadas com dois produtos a base de aminoácidos na dose comercial e no dobro da dose foi realizado um experimento em Ituverava, SP. Foram empregados cinco tratamentos em 3 lotes de sementes do milho híbrido DKB 214, um destes tratamentos serviu de testemunha (T1); no segundo tratamento foi usado o produto 1, dose comercial (T2); o terceiro tratamento foi feito com o mesmo produto, com o dobro da dose recomendada comercialmente (T3), o quarto tratamento foi composto pelo produto 2 na dose comercial (T4) e o quinto tratamento (T5) foi adicionado o produto 2 no dobro da dose recomendada comercialmente. Para verificar o desempenho de tais produtos e das duas doses realizou-se a semeadura em campo sendo os tratamentos distribuídos em blocos ao acaso para cada lote. Avaliou-se o desempenho inicial dos três lotes pela porcentagem de plântulas emersas aos 5, 6 e 12 dias após a semeadura; pelo IVE (índice de velocidade de emergência) e pela massa seca da parte aérea e do sistema radicular das plantas de milho colhidas após trinta dias da semeadura. Pela análise estatística dos dados não houve efeito significativo dos tratamentos e das doses utilizadas no desempenho inicial de lotes de sementes de milho de alta qualidade semeados em boas condições de campo.
\end{abstract}

Palavras-chave: Nutrientes. Tratamento de semente. Zea mays. Dosagem.

SUMMARY: With the goal of evaluate the initial performance in the field of corn seeds treated with aminoacids had been analyzed an experiment in Ituverava, São Paulo state. It had been done five treatments in lots of hybrid corn seeds DKB 214, one of these treatments were witness (T1), in the second treatment had been used the first product, commercial dose (T2); the third treatment had been done with the same product, with the double of the dose recommended commercially (T3); the fourth treatment had been composed by the second product in the commercial dose (T4) and the last treatment had been added to the second commercial product the double of the dose recommended commercially. To verify the performance of these products and of both doses had been done the sowing in field, being the treatments distributed in blocks by case for each lot. It had been evaluated the initial performance of the three lots by the percentage of emerged seedlings in the fifth, sixth and twelfth day, by the IVE (speed of emergence index) and by the plants dry weight after thirty days of the sowing. Through the statistical analysis of the information there wasn't significant effect of the treatments and of the doses used in the initial performance of the high quality lots sown in good conditions of field.

Keywords: Nutrient. Seeds Treatment. Zea mays. Dose.

\section{INTRODUÇÃOO}

O milho (Zea mays L.) é considerado uma das principais espécies utilizadas no mundo, devido à sua multiplicidade de aplicações, quer na alimentação humana, quer na

\footnotetext{
${ }^{1}$ Profa. Dra. em Agronomia, FEI/FAFRAM, Ituverava. E-mail: svsegato@ carol.com.br ${ }^{2}$ Engenheiro Agrônomo
} 
alimentação animal, assume relevante papel sócio-econômico, além de constituir-se em indispensável matéria-prima para diversificados complexos agroindustriais.

Produtores de milho têm tido a sua disposição uma vasta linha de produtos que visam aumentar o potencial produtivo da cultura e dentre as novas tecnologias estão o tratamento de sementes com aminoácidos.

De acordo com Brasil (1975) os aminoácidos são as unidades estruturais das moléculas de proteína e fazem parte das vias do metabolismo intermediário de açúcares e ácidos orgânicos, devendo também, participar do metabolismo de lipídeos e até contribuir como fonte de energia para a célula, quando entram no Ciclo de Krebs.

Segundo Kikuti; Tanaka (2006) a utilização de aminoácidos e nutrientes na cultura do feijão, não proporcionou alterações significativas nos teores foliares de nutrientes. $\mathrm{O}$ aminoácido não foi eficiente para aumentar a produtividade do feijoeiro em condições de alta população de plantas.

Silva et al. (1991) utilizando um composto orgânico liquido, de origem animal, contendo principalmente aminoácidos e proteínas solúveis associadas a sais minerais na cultura do repolho indicaram que pulverizações foliares ou em tratamento de sementes não influenciaram a qualidade das mudas produzidas em viveiro. Tais autores sugeriram a realização de ensaios com a aplicação desse produto em culturas não adubadas ou fracamente adubadas de repolho e outras espécies, para verificar se existem condições nas quais o produto tenha eficiência satisfatória.

Assim, o desempenho em campo de sementes de milho tratadas com produtos que tem como base aminoácidos associados a outros compostos nutritivos ainda demandam estudos, o que torna viável a elaboração de pesquisa com o objetivo de avaliar o desempenho inicial em campo de sementes de milho tratadas com aminoácidos em duas dosagens.

\section{MATERIAL E MÉTODOS}

Caracterização do híbrido. O experimento foi conduzido com 3 lotes comerciais de sementes do milho híbrido simples DKB 214, de mesma classificação (C2L). Tais sementes comercialmente vêm tratadas com os produtos Actellic e K-obiol - 40 mL/t; Haiten - 11 mL/t e Maxim - $1500 \mathrm{~mL} / \mathrm{t}$.

O híbrido simples DKB 214 possui as seguintes características: porte baixo, grande expansão de espigas, ótimo espalhamento, grãos semiduros de elevado peso específico e ótima qualidade de colmo, por isso o hibrido é ideal para o exigente mercado de alta 
tecnologia. O híbrido é precoce, com florescimento com 810 GDU, Dry-Down bom e Stay Green bom, os grãos são semiduro de cor amarelo-alaranjado, alta tolerância a grãos ardidos e possui um excelente empalhamento. Altura da planta é de 2,20 - 2,30 m, a inserção da espiga varia de 1,15 a 1,25 m e as folhas são semi-eretas, possui colmo de alta sanidade, ou seja, alta resistência ao quebramento possui um bom sistema radicular. A sua recomendação de semeaduras nas áreas de 500 a 700 m em época normal e população de 55 a 60 mil plantas por hectare (DEKALB, 2006).

Caracterização dos tratamentos. Inicialmente foi determinado o teor de água dos lotes. De posse do teor de água dos lotes, estes foram divididos em cinco porções. Uma destas porções serviu de testemunha, portanto sem tratamento (T1); a segunda porção foi tratada com o produto 1 (Bioamino ${ }^{\circledR}$ Extra), na dose comercial de $100 \mathrm{~mL}$ do produto comercial por hectare de milho (T2), a terceira porção foi tratada com o mesmo produto (Bioamino ${ }^{\circledR}$ Extra), com o dobro da dose recomendada comercialmente, ou seja $200 \mathrm{~mL}$ do produto comercial por hectare de milho (T3), o quarto tratamento foi composto pelo produto 2 (Nobrico Star) de outra empresa na dose comercial de $200 \mathrm{~mL}$ do produto comercial por $100 \mathrm{~kg}$ de sementes de milho (T4) e o quinto, último tratamento (T5) foi adicionado o produto comercial 2 (Nobrico Star) no dobro da dose recomendada comercialmente $(400 \mathrm{~mL}$ do produto comercial por $100 \mathrm{~kg}$ de semente).

Caracterização dos produtos. O produto 1, Bioamino ${ }^{\circledR}$ Extra, tem por objetivo melhorar o metabolismo geral das plantas ativando a fotossíntese e estimulando a síntese de proteínas. O Bioamino ${ }^{\circledR}$ Extra reduz os compostos solúveis tomando as plantas mais tolerantes e resistentes às doenças e as pragas, porém sua função é de proporcionar maior desenvolvimento radicular, favorecer a absorção de macronutrientes e micronutrientes e mais rápida recuperação da cultura frente à situação de estresse. Devido à maior translocação de aminoácidos no interior da planta ela irá ter maior número de frutos e grãos, favorecendo a uniformidade da colheita, aumentando o peso do fruto/grãos acarretando maior teor de sólidos solúveis nos frutos. Sua composição química é constituída por nitrogênio $(\mathrm{N})=3 \%(37,5$ $\mathrm{g} /$ litro), matéria orgânica $(\mathrm{MO})=40 \%$ (500 g/litro), relação $\mathrm{C} / \mathrm{N}=6,5 ; \mathrm{pH}=6,5$; densidade $=$ $1250 \mathrm{~g} / \mathrm{L}$ e dose $=100 \mathrm{~mL} /$ ha $($ BIO SOJA, 2006). O produto 2, Nobrico Star, é um produto criado para estimular e melhorar o desenvolvimento do sistema radicular e ao mesmo tempo, uma fonte completa e equilibrada de nutrientes para a planta. Estimular todas as fases do desenvolvimento, melhorar a estrutura do solo, a flora microbiana e agir na liberação de nutrientes bloqueados no solo. Sua composição química é constituída por potássio 2,5\%, cobalto $0,04 \%$, boro $0,03 \%$, zinco $0,07 \%$, magnésio $0,06 \%$, cobre $0,07 \%$, ferro $0,14 \%$, 
polissacarídeos $6,2 \%$, extrato de algas $2 \%$, aminoácidos livres $6 \%$, ácidos fúlvicos $15,0 \%$, ácidos húmicos $0,5 \%$, extrato húmico total $15,5 \%$, matéria orgânica total $23,6 \%$; densidade:1,3 kg/L e pH:5,5 (AMINOAGRO, 2005).

Local, instalação e condução do experimento. O ensaio foi realizado em campo, na Faculdade de Agronomia "Dr. Francisco Maeda", em Ituverava/SP. "A semeadura foi realizada no dia 19/11/2005 em uma área situada a 20²0'30” de latitude S e 4747’30" de longitude W. O local escolhido apresenta altitude de aproximadamente $631 \mathrm{~m}$ e o solo apresenta característica de um Latossolo roxo. Os dados coletados na estação meteorológica indicaram temperatura média de aproximadamente $24^{\circ} \mathrm{C}$ e precipitação de $770 \mathrm{~mm}$ bem distribuída no período. O solo foi preparado de forma convencional, corrigido e adubado de acordo com a recomendação do Boletim 100 (RAIJ et al., 1996) para a cultura do milho. Quando necessário, foi feito o controle de plantas daninhas através da capina manual (entrelinha) e/ou monda (linha) e aplicação de inseticida de forma homogênea em todos os tratamentos.

Avaliações. Emergência de plântulas em campo. Conduzido de acordo com as recomendações de Nakagawa (1999), empregando-se 200 sementes de cada tratamento em quatro repetições de 50 sementes. As sementes de cada repetição foram semeadas a $3 \mathrm{~cm}$ de profundidade, em linhas de 10,0 m de comprimento espaçadas de $90 \mathrm{~cm}$. A contagem das plântulas emersas foi feita aos 5, 6, e 12 dias após a semeadura. Índice de velocidade de emergência (IVE). Foi conduzido anotando-se, de 24 em 24 horas, o número de plântulas que emergiram, ou seja, as que apresentaram coleóptilo acima da superfície do solo, até o décimo segundo dia. Ao final, foi calculado o IVE, empregando-se a fórmula proposta por Maguire (1962). Massa seca da parte aérea (MSpa). Foram cortadas, ao nível do solo, amostras ao acaso, composta por cinco partes aéreas de plantas consecutivas de cada linha, aos 30 dias após semeadura. Cada uma das repetições foi acondicionada em sacos de papel, identificados, e levados à estufa com circulação de ar forçada, e mantida à temperatura de $80^{\circ} \mathrm{C}$ por 24 horas. Após este período, cada repetição foi pesada com o auxílio de uma balança de precisão de três casas decimais, e os resultados médios expressados em gramas por planta (NAKAGAWA, 1999). Massa seca do sistema radicular (MSsr). Aos 30 dias após semeadura, três plantas de cada linha foram coletadas ao acaso e em sequiência, adicionandose água ao solo e removendo a terra manualmente e com enxadão. Foram arrancadas, separando-as dos seus sistemas radiculares (cortadas ao nível do solo) os quais foram lavados. Cada uma das repetições foi acondicionada em sacos de papel, identificados, e levados à estufa com circulação de ar forçada, e mantida à temperatura de $80^{\circ} \mathrm{C}$ por um período de 24 
horas (NAKAGAWA, 1999). Após este período, cada repetição foi pesada com o auxílio de uma balança de precisão de três casas decimais, e os resultados médios expressados em gramas por planta. Esta determinação foi realizada apenas para o lote 1.

Procedimento estatístico. Foi utilizado o delineamento experimental em blocos casualizado em esquema fatorial de $2 \times 2$ mais testemunha ( 2 produtos $\times 2$ doses mais testemunha sem tratamento) e empregado o teste $\mathrm{F}$ para a análise de variância dos dados. As médias dentro de cada lote foram comparadas pelo teste de Tukey a 5\% de probabilidade. As repetições e o número de sementes analisadas estão na metodologia de cada teste realizado. Não foi realizada transformação nos dados originais.

\section{RESULTADO E DISCUSSÃO}

Os dados médios das avaliações realizadas em campo encontram-se nas Figuras numeradas de 1 a 6.

Optou-se em não colocar a análise estatística dos dados, pois não houve interação significativa entre os dois produtos usados e as duas doses empregadas em nenhuma das análises realizadas. Também não houve significância dos fatores isolados estudados, exceto para o lote 3 na avaliação da emergência das plântulas de milho em campo aos 5 dias após a semeadura (Figura 1), onde o fator isolado dose teve diferença significativa. No caso a maior dose foi prejudicial à emergência das plântulas para esse lote.

Na Figura 1 os resultados médios obtidos 5 dias após semeadura não mostraram diferença significativa entre os produtos e as doses utilizadas. Com 5 dias as sementes do lote 1 haviam produzido plântulas que variaram de 68 a $74 \%$ de emergência. Os produtos utilizados no dobro das doses recomendadas aceleram esta primeira contagem, em relação à testemunha e aos produtos da dose recomendada comercialmente, embora não tenha sido significativo tal resultado. O lote 2 teve desempenho inferior ao lote 1 , nesta primeira contagem (59 a 70\%). A testemunha emergiu somente 59\%, tendo pior desempenho que as sementes tratadas. Neste lote, a dose comercial proporcionou maior porcentagem de emergência inicial, para ambos os produtos. Para o lote 3, ainda na Figura 1, o tratamento não apresentou vantagens no arranque inicial, visto que a testemunha, o produto 1 e o 2 nas doses comerciais obtiveram mesma emergência (75\%). Este lote, em termos de rapidez em estabelecer o estande foi superior aos lotes 1 e 2, talvez em função desta superioridade, não tenha havido mesmo vantagem em tratar a semente. Neste caso ainda, o dobro da dose 
diminui significativamente a velocidade de emergência inicial, principalmente para o produto 1.

Embora não tendo feita análise estatística comparando lotes, pelos valores obtidos é possível verificar que o lote 3 foi superior ao lote 1 , tendo o lote 2 menor velocidade de emergência inicial (Figura 1), aparentemente o tratamento surtiu mais efeito no lote classificado como o de menor velocidade de emergência, neste o tratamento com os produtos na dose comercial ajudou no arranque inicial. Segundo Carvalho e Nakagawa (2000) o nível de vigor das sementes por ocasião da semeadura tem um pronunciado efeito sobre sua resposta ao tratamento com fungicida. Sementes de alto vigor não reagem ao tratamento químico; as de vigor médio reagem até certo ponto, com uma intensidade crescente à medida que cai o nível de vigor; desse ponto em diante o índice de resposta é cada vez menor e as sementes de baixo vigor, praticamente, não reagem ao tratamento químico com fungicidas. Pode-se inferir que o tratamento de sementes tanto de fungicida quanto de outros produtos tende a seguir as mesmas premissas, ou seja, lotes de baixa qualidade ou de altíssima qualidade respondem proporcionalmente menos ao tratamento de suas sementes que lotes de qualidade intermediária.

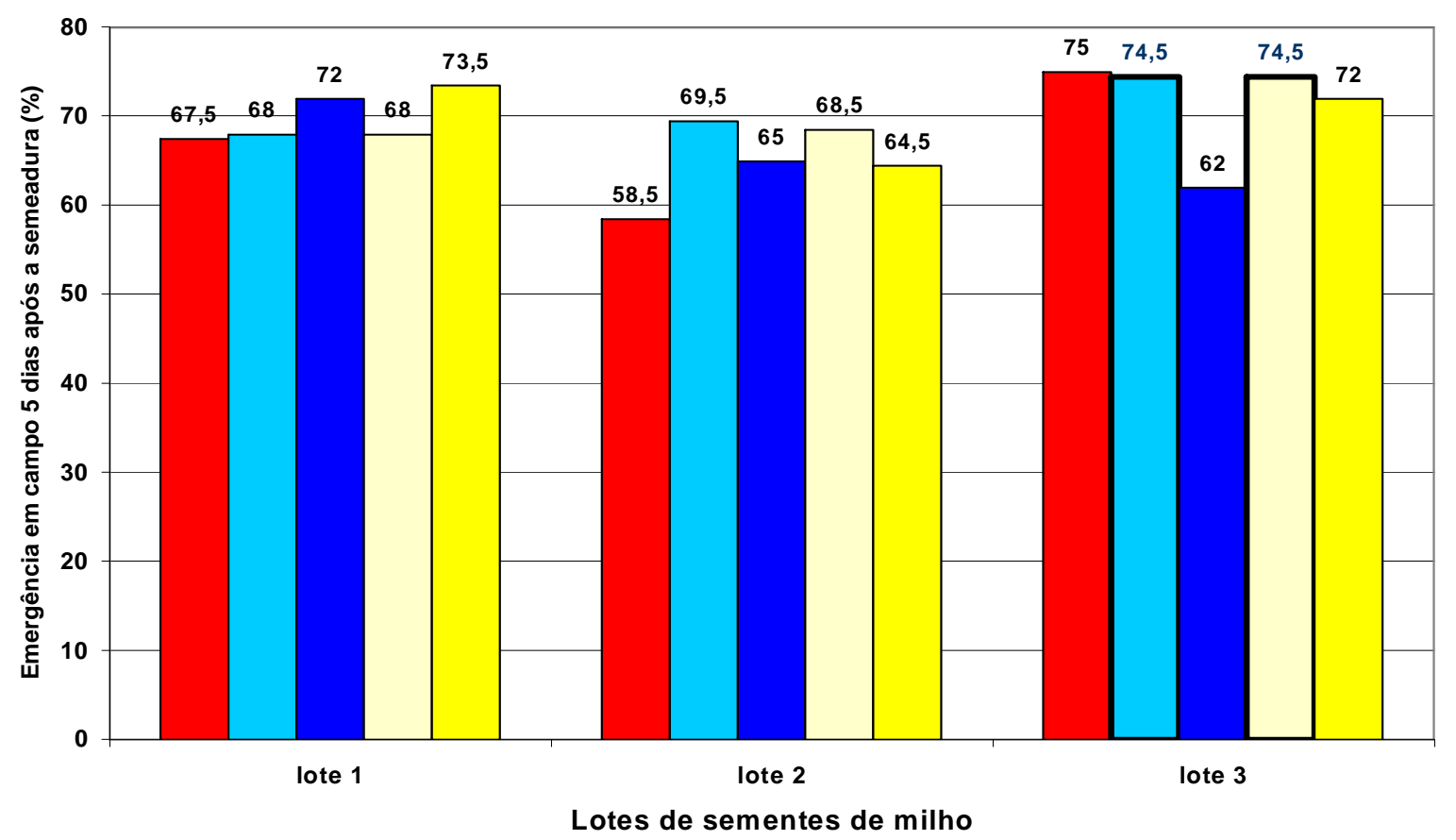

$\square$ TESTEMUNHA $\square$ P1D1 $\square$ P1D2 $\square$ P2D1 $\square$ P2D2

FIGURA 01 - Dados médios de emergência em campo 5 dias após a semeadura (\%) dos três lotes de sementes de milho DKB 214 utilizado no experimento tratados com dois produtos a base de aminoácidos (P1: produto 1 e $\mathrm{P} 2$ : produto 2 ), associados a duas dosagens (D1:comercial e D2: dobro da dose) e testemunha sem tratamento. Coeficiente de variação (CV-\%) para lote 1, 2 e 3 respectivamente de 18,39; 19,97 e 8,81. 
Observando-se a Figura 2, nota-se pelos resultados que a emergência em campo 6 dias após a semeadura não diferiu novamente estatisticamente os lotes, produtos, doses, mas a tendência do ranqueamento do lote 3 como mais veloz que o lote 1 e este mais veloz que o lote 2 se manteve. No lote 1 a emergência variou de 83\% (P2D1) a 90\% (P2D2). A testemunha e produto 1 em ambas doses tiveram emergência de $85 \%$ de suas plântulas já no sexto dia. O lote 2 teve a testemunha com $82 \%$ de emergência e $87 \%$ do P1D2. Também a dose 2 foi superior a testemunha no produto 2. A tendência descrita na Figura 1, para o lote 3 permaneceu e acentuou-se, ou seja, não vantagem do tratamento com os produtos em relação a testemunha e, ainda, o dobro da dose promoveu menor velocidade de emergência.

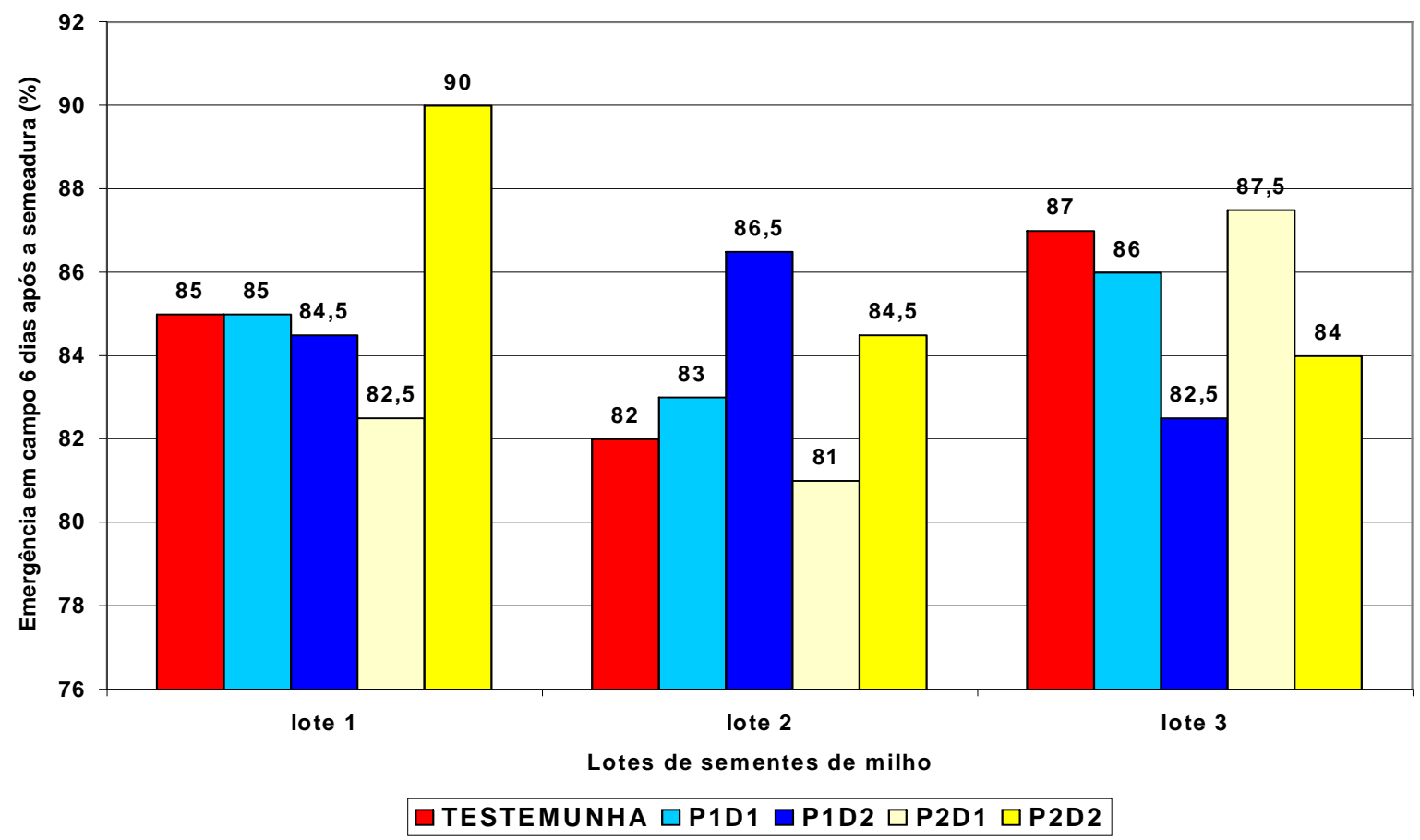

FIGURA 02 - Dados médios da avaliação de emergência em campo 6 dias após a semeadura (\%) dos três lotes de sementes de milho DKB 214 utilizado no experimento tratados com dois produtos a base de aminoácidos (P1: produto 1 e $\mathrm{P} 2$ : produrto 2), associados a duas dosagens (D1:comercial e D2: dobro da dose) e testemunha sem tratamento. Coeficiente de variação (CV-\%) para lote 1, 2 e 3 respectivamente de 9,43; 11,49 e 6,42.

Na Figura 3 o índice de velocidade de emergência (IVE) variou de 8,3 a 9,0, indicando rápido desenvolvimento inicial dos lotes utilizados. O IVE acompanha a tendência verificada nas contagens de emergência ao quinto e sexto dia, ou seja, o lote 3 estabeleceu-se primeiro $(8,7)$ que lote $1(8,6)$ e o menos veloz foi o lote $2(8,4)$, mas nada novamente foi significativo. Para lote 1, produtos com o dobro da dose tiveram maior IVE que testemunha e produtos na dose comercial tiveram menor IVE que testemunha. Para lote 2, tratamentos foram melhores 
que testemunha, mas o dobro da dose teve também maior IVE para ambos produtos. Para lote 3 só dose comercial teve mesma velocidade de emergência que testemunha, enquanto que dobro da dose menor velocidade.

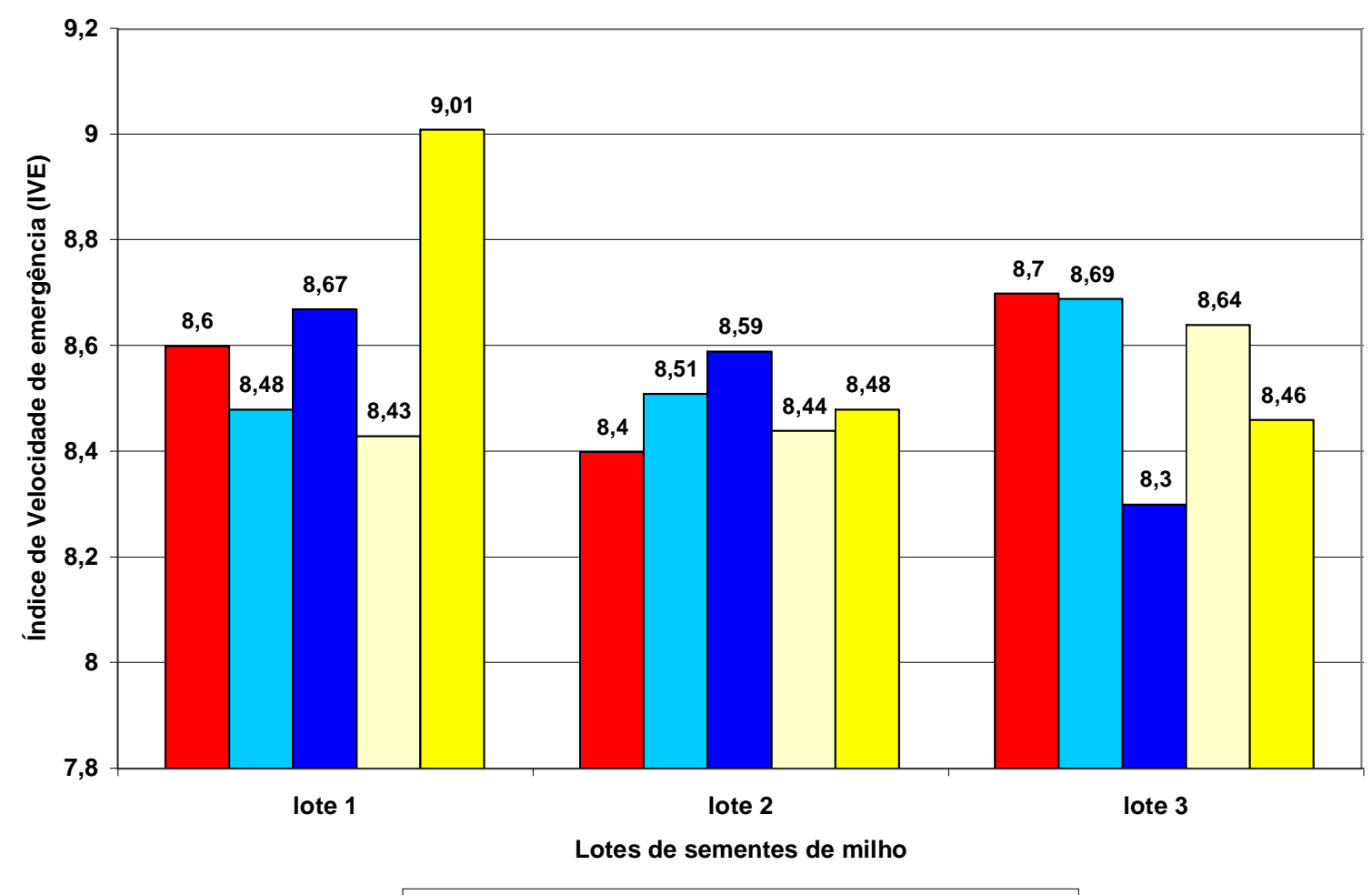

$\square$ TESTEMUNHA $\square$ P1D1 $\square$ P1D2 $\square$ P2D1 $\square$ P2D2

FIGURA 03 - Dados médios do índice de velocidade de emergência (IVE) dos três lotes de sementes de milho DKB 214 utilizado no experimento tratados com dois produtos a base de aminoácidos (P1: produto 1 e P2: produrto 2), associados a duas dosagens (D1:comercial e D2: dobro da dose) e testemunha sem tratamento. Coeficiente de variação (CV-\%) para lote 1, 2 e 3 respectivamente de 7,23; 7,74 e 4,97.

Observando-se os dados contidos na Figura 4, verifica-se tratar de lotes de alta qualidade, visto que a emergência final variou de 89 a $95 \%$. Neste sentido, tais produtos e doses empregadas não resultaram significativamente em maior estande.

$\mathrm{Na}$ emergência em campo final aos 12 dias (Figura 4) que definiu o estande, para o lote 1 , só o dobro do produto $2(95 \%)$ foi melhor que a testemunha $(93 \%)$ a dose 2 produto 1 foi semelhante à testemunha, mas a dose comercial de ambos produtos apresentou $90 \%$ de emergência final, portanto não houve vantagem em se tratar as sementes na dose comercial para ambos produtos, tendo tendência para o lote 1 de imprimir menor emergência do que se não houvesse tratado. Pelo índice de velocidade de emergência (Figura 3) a tendência foi a mesma. Portanto, no lote 1 a maior velocidade de emergência promoveu maior estande final. Em ambos os casos o produto2 no dobro da dose comercial foi melhor embora não significativamente. 


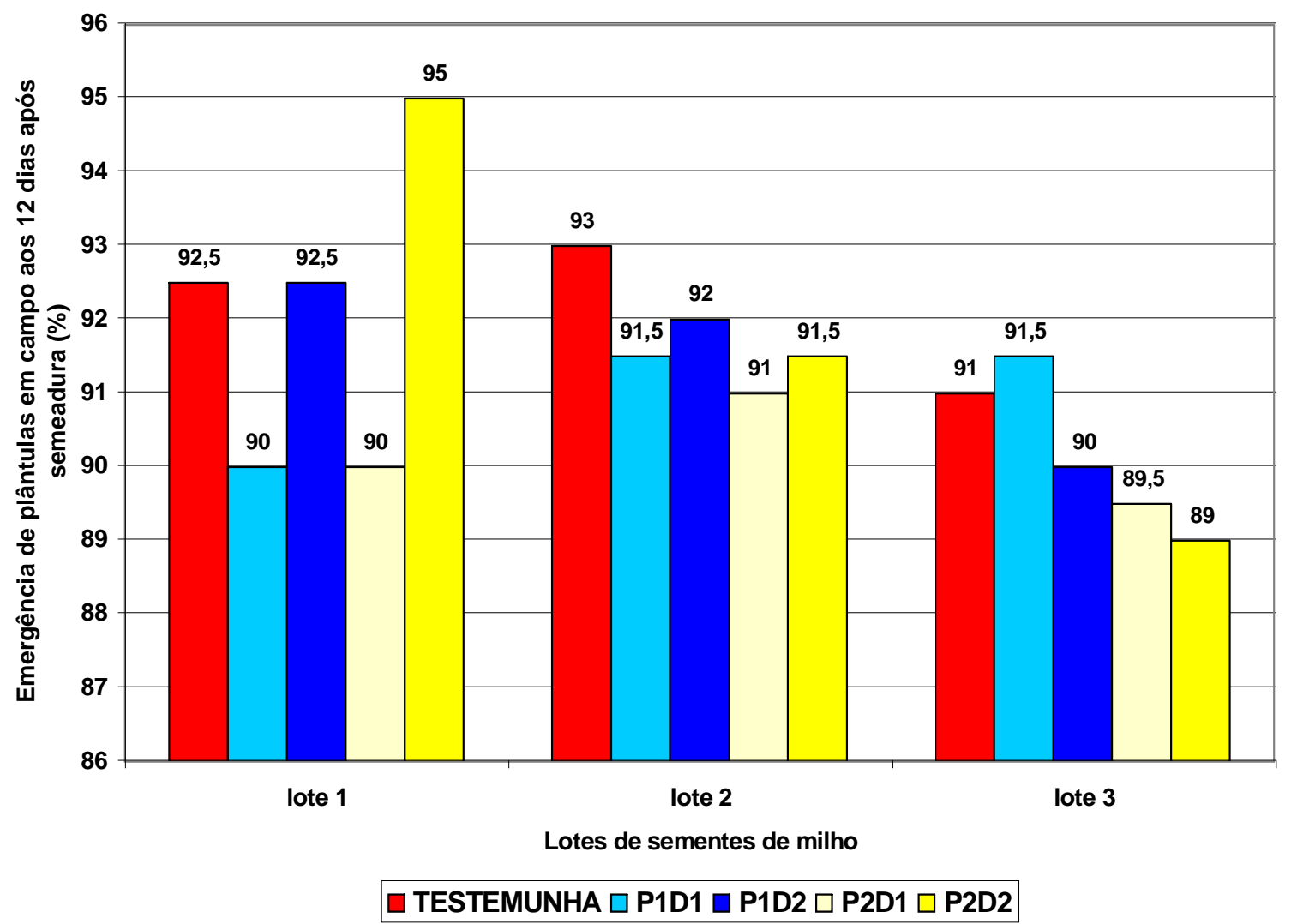

FIGURA 04 - Dados médios da emergência de plântulas em campo aos 12 dias após a semeadura (\%) dos três lotes de sementes de milho DKB 214 utilizado no experimento tratados com dois produtos a base de aminoácidos (P1: produto 1 e P2: produto 2), associados a duas dosagens (D1: comercial e D2: dobro da dose) e testemunha sem tratamento. Coeficiente de variação (CV-\%) para lote 1,2 e 3 respectivamente de 4,58; 4,50 e 4,51.

Para o lote 2, a tendência observada no lote 1 na emergência final em campo (Figura 4) se manteve, mas a testemunha foi melhor. Na verdade houve pouca diferença entre os tratamentos (93 a 91\%), portanto não se recomendaria o tratamento, mas em termos de velocidade de emergência (Figura 3) para o lote 2 todos os tratamentos empregados foram melhores, principalmente o dobro da dose, mas a velocidade de emergência também neste caso foi muito parecida com a testemunha que teve um pouco menos de velocidade de emergência $(8,4$ a 8,6$)$.

Para o lote 3, a emergência final em campo (Figura 4) foi muito semelhante à testemunha, dados variaram de 89 a 92\%, mas o dobro da dose comercial resultou em um pior estande que na dose comercial, portanto para o lote 3 não houve vantagem de dobrar a dose sendo assim não compensaria realizar tratamento e usar mais produto traria problemas. Já pelo índice de velocidade de emergência (Figura 3) a velocidade de estabelecimento demonstrou de forma mais clara a tendência verificada na emergência final em campo (Figura 4), ou seja, menor velocidade resultou em menor população. 
Portanto, de modo geral, o índice de velocidade de emergência (Figura 3) e a emergência final em campo (Figura 4) na dose comercial não apresentaram vantagem. No entanto, o dobro da dose deve ser mais bem investigado, pois há diferenças entre lotes tanto positivas (melhorar velocidade e estande) quanto negativa (piorar desempenho em termos de velocidade e estande, vide lote 3). Embora valha a pena enfatizar que praticamente nenhum resultado (tendência descrita) foi significativo estatisticamente, nem pelo teste de comparação de médias (Tukey 5\%), nem pela análise de variação dos dados. Notam-se lotes que mesmo sem tratamento apresentaram desempenhos muito semelhantes entre si: 93,93 e $91 \%$ de emergência final respectivamente para lote 1,2 e 3.

De modo geral, os resultados mostram que a matéria seca da partes aéreas colhidas das plantas aos 30 dias apresentou desempenho semelhante dos lotes em transferir matéria seca da semente para a parte aérea das plantas (Figura 5), qualquer que fosse o tratamento de semente empregado (6,1 a 7,7 g/planta). Nas testemunhas de cada lote é possível verificar a mesma tendência da primeira contagem ao quinto dia (Figura 1), sexto dia (Figura 2) e do índice de velocidade de emergência que apontaram uma tendência de maior desempenho do lote 3 $(7,3 \mathrm{~g})$, seguido pelo lote $1(6,5 \mathrm{~g})$ e de menor desempenho do lote $2(6,3 \mathrm{~g})$. Isto mostra que há relação positiva entre a velocidade de emergência e a eficiência de transferência de matéria seca da semente para a plântula (Figura 5).

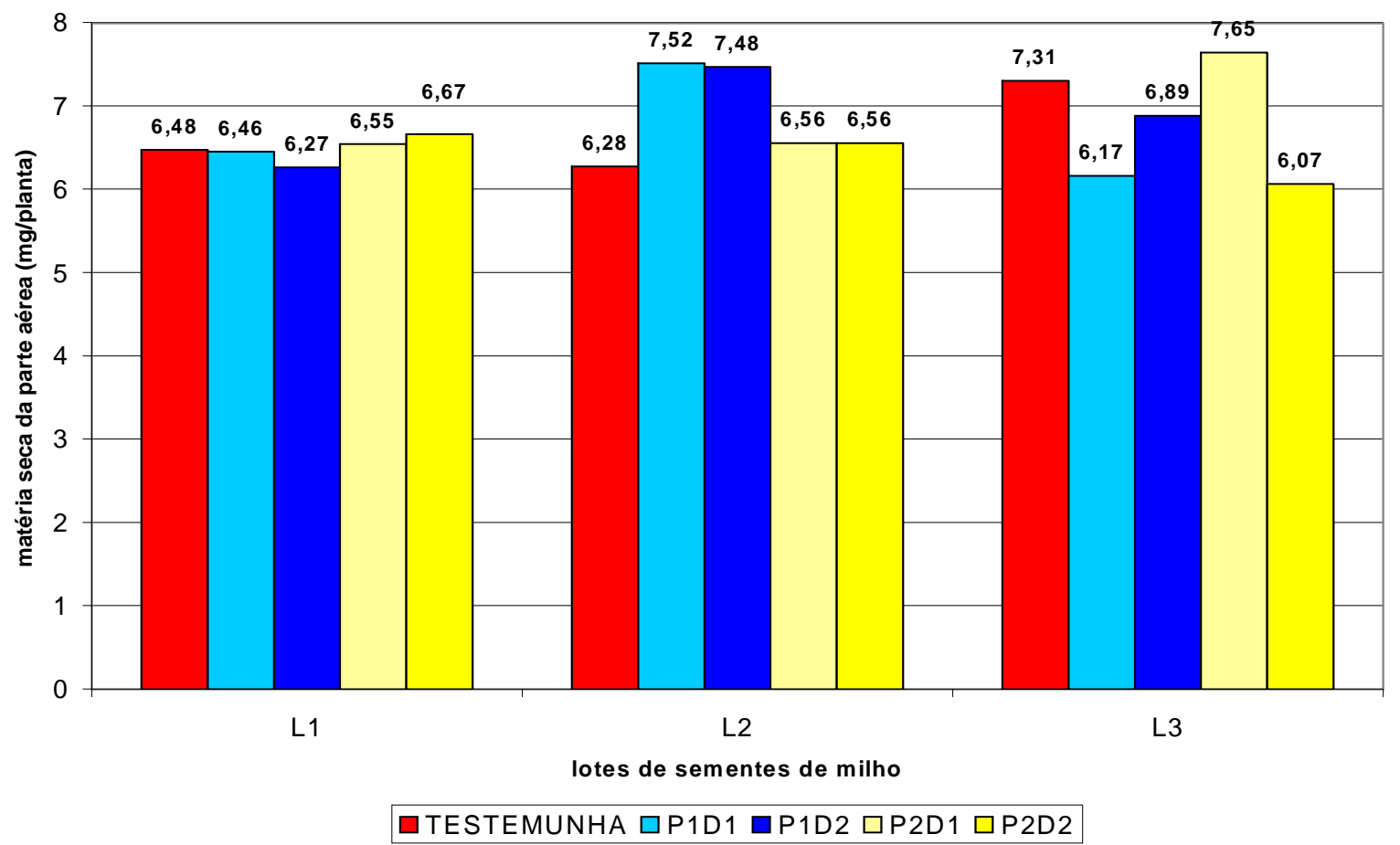

FIGURA 05 - Dados médios da matéria seca da parte aérea das plantas (g por planta) dos três lotes de sementes de milho DKB 214 utilizado no experimento tratados com dois produtos a base de aminoácidos (P1: produto 1 e P2: produto 2), associados a duas dosagens (D1: 
comercial e D2: dobro da dose) e testemunha sem tratamento. Coeficiente de variação (CV$\%)$ para lote 1,2 e 3 respectivamente de 19,55; 26,37 e 21,09.

Analisando cada lote separadamente (Figura 5), observa-se que o lote 1 foi o lote que mostrou menor variação entre tratamentos ( 6,3 a 6,7g/planta), não vale aqui usar o tratamento de semente, pois a transferência de matéria seca foi boa com ou sem o tratamento.

Para o lote 2 (Figura 5) o produto 1 (ambas doses) e também, mas menos expressivamente o produto 2 (ambas doses) conseguiu transferir mais matéria seca, pois teve maior velocidade de emergência (Figura 3). A resposta mostra que o aumento da velocidade é que fez com que sementes tratadas com ambos os produtos em qualquer dose acumulassem mais matéria seca. Houve certa relação entre o aumento da velocidade de emergência e a transferência de matéria seca. Para esse lote os produtos, mesmo na dose 1, foram superiores a testemunha valendo investigar melhor. Talvez isto tenha ocorrido por tratar-se do lote de menor vigor aparentemente.

Já para o lote 3 , somente o produto 2 na dose comercial transferiu mais matéria seca que a testemunha, os demais produtos foram piores que a testemunha. Existiu também neste lote relação entre o índice de velocidade de emergência e peso de matéria seca.

Observando os dados como um todo (Figura 5), estaticamente não compensa fazer o tratamento de sementes com aminoácidos em termos de aumento de velocidade e de acúmulo de matéria seca, mas percebe-se que há certa interação entre lotes embora não significativa frente à resposta tendo casos em que há até ganho em matéria seca mesmo na dose comercial recomendada: produto 2 na dose comercial para os lote 1,2 e 3 ; e o produto 1 na dose comercial para lote 2 .

Aparentemente o produto 2 foi mais eficiente que o produto 1, pois teve tendência em ganhos de peso mais constantes em relação à testemunha que o produto 1 .

Por motivos técnicos apenas para o lote 1 foi avaliado o peso de matéria seca do sistema radicular. A Figura 6 traz tais dados e novamente o sistema radicular só foi mais vigoroso que a testemunha quando foi usado o produto na dose comercial. Mesmo para o lote 1 que foi o que menos resposta apresentou na parte aérea, o sistema radicular mostrou um certo desempenho. Na Figura 6 apesar de não haver diferença significativa entre os dados o uso do dobro da dose resultou em menor massa seca de raiz para ambos os produtos, mostrando a necessidade de dosar corretamente os produtos em campo.

De modo geral, quando se observam os dados das Figuras 1, 2, 3, 4, 5 e 6 verifica-se que as respostas no desempenho inicial não são significativas para justificar o uso de tais produtos em lotes de sementes de milho de alta qualidade (emergência final variou de $89 \%$ a 
95\% entre lotes e os tratamentos de sementes). Segundo Carvalho e Nakagawa (2000) nestas condições existem menor resposta ao tratamento de sementes. Trabalhando com produtos a base de aminoácidos Silva et al. (1991) e Kikuti; Tanaka (2006) não constataram efeito significativo desses produtos para a cultura do repolho e do feijão, respectivamente.

No entanto ainda assim no experimento com sementes de milho observa-se um sensível ganho no desenvolvimento para alguns lotes, principalmente quando tratados com o produto 2 mesmo na dose comercial. Tal produto apresenta em sua fórmula uma série de nutrientes (K, $\mathrm{Co}, \mathrm{B}, \mathrm{Zn}, \mathrm{Mg}, \mathrm{Cu}, \mathrm{Fe}$ ) e de outros compostos, entre eles $6 \%$ de aminoácidos e que segundo o fabricante (FOLHA AMINOAGRO, 2005) visa estimular e melhorar o desenvolvimento radicular entre outros benefícios.

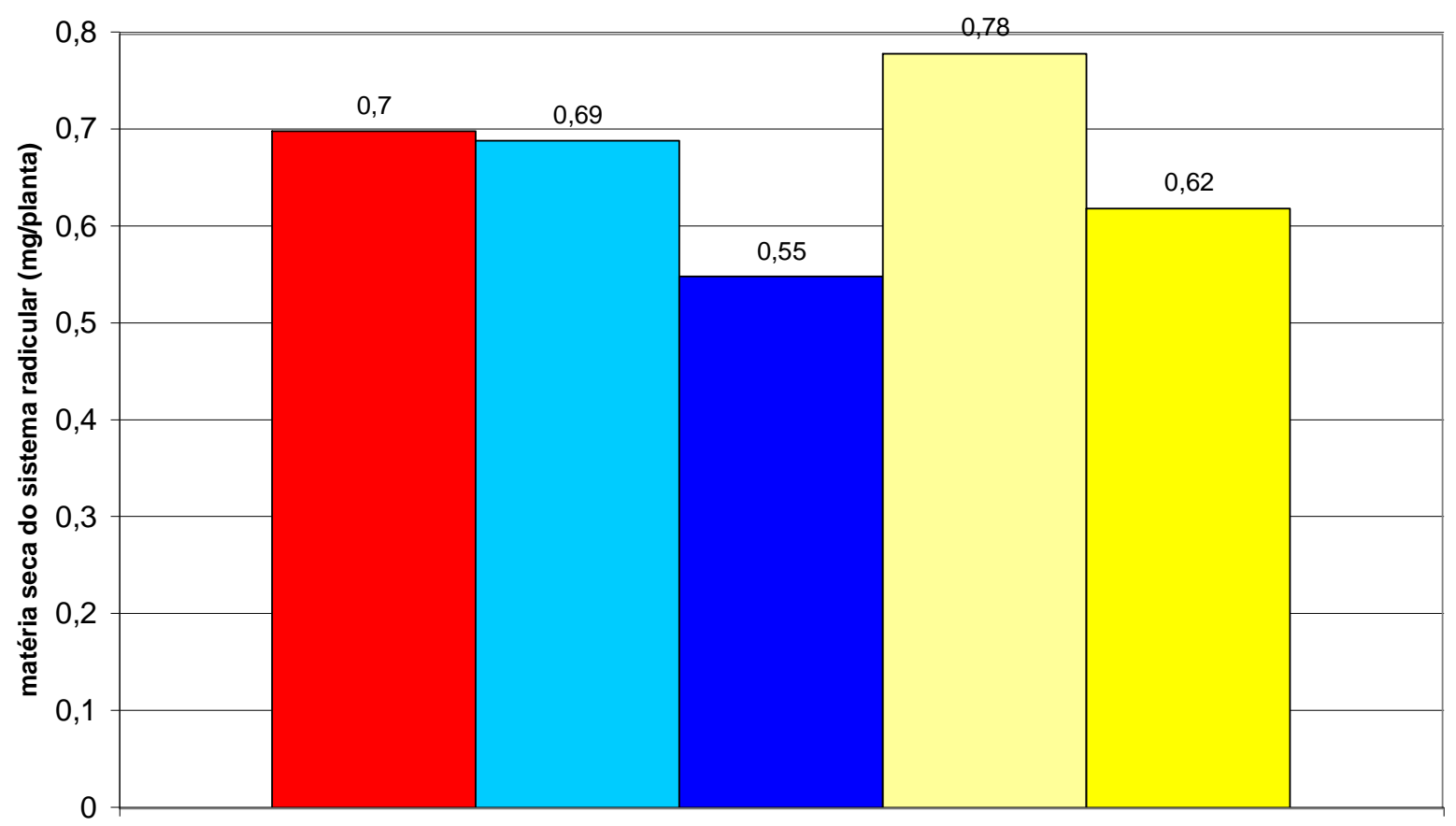

L1

lote de semente de milho

TESTEMUNHA $\square$ P1D1 $\square$ P1D2 $\square$ P2D1 $\square$ P2D2

FIGURA 06 - Dados médios da avaliação da matéria seca do sistema radicular das plantas (g por planta) do lote 1 de sementes de milho DKB 214 utilizado no experimento tratados com dois produtos a base de aminoácidos (P1: produto 1 e P2: produto 2), associados a duas dosagens (D1: comercial e D2: dobro da dose) e testemunha sem tratamento. Coeficiente de variação para lote 1 de $35,10 \%$.

Em um próximo trabalho vale à pena usar lotes e/ou condições ambientais diferentes, para prover mais subsídios quanto à recomendação de tais produtos, visto que nesse ensaio onde se empregaram lotes de qualidade superior e as condições ambientais foram propícias ao 
desenvolvimento inicial das plantas não houve efeito significativo para recomendar o tratamento de sementes de milho com os produtos a base de aminoácidos nas doses avaliadas.

\section{CONCLUSÃO}

Pode-se concluir que nas condições que foi conduzido o trabalho (boas condições em campo associada a lotes de sementes de milho de alta qualidade) não houve efeito significativo dos tratamentos de sementes com produtos a base de aminoácidos nem na dose comercial, nem com o dobro dessa dosagem.

\section{REFERÊNCIAS}

AMINOAGRO, Nobrico Star. Folha Aminoagro. Produto do mês, Brasília: Aminoácidos, ano 4, n.10, abril 2005. (Folheto)

BIO SOJA. Bioamino Premium: fertilizante foliar de alta performance. São Joaquim da Barra: Bio Soja, [2006]. (Folheto).

BRASIL, O. G. Constituição ao estudo do acetato ${ }^{14} \mathrm{C}$ como precursor de aminoácidos em folhas destacadas de café (Coffea arábica L. cv. Mundo Novo). Piracicaba: ESALQ - USP, 1975. 41p.

CARVALHO, N.M.; NAKAGAWA, J. Sementes: ciência, tecnologia e produção. 4.ed. Jaboticabal: Funep, 2000. 588p.

DEKALB, Safra verão 05/06. Disponível em: http://www.dekalb.com.br/dkb214.asp. Acesso em: 05 mar. 2006.

KIKUTI, H.; TANAKA R. T. Produtividade e qualidade de sementes de feijão em função da aplicação de aminoácidos e nutrientes. Disponível em:

www.cnpaf.embrapa.br/conaf/indice/autos431.html. Acesso em: 05 mar. 2006.

MAGUIRE, J.D. Speed of germination -aid in selection and evaluation for seedling and vigour. Crop Science, Madison, v.2, n.2, p.176-177. 1962.

NAKAGAWA, J. Testes de vigor baseados no desempenho das plântulas. In: KRZYZANOWSKI, F.C.; VIEIRA, R.D.; FRANÇA NETO, J.B. (Ed.). Vigor de sementes: conceitos e testes. Londrina: ABRATES, 1999. 218p. cap.2, p.1-24.

RAIJ, B. Van et al. (Ed.). Recomendações de adubação e calagem para o Estado de São Paulo. 2.ed. Campinas : Instituto Agronômico, 1996. 285p. (IAC. Boletim técnico, 100).

SILVA, N. F.; BORGES, J. D.; VIEIRA, R. M. Efeito do orgasol na cultura de brassica oleracea var. capitata 1, cv. Kenzan. Pesquisa Agropecuária Brasileira, Brasília, v 26 n. 11/12, p.1897-1900, 1991. 
